\title{
Impact of social media on children's relationship with brands
}

\author{
Nikoleta Hutmanová ${ }^{1, *}$ and Peter Dorčák ${ }^{1}$ \\ ${ }^{1}$ University of Economics in Bratislava, Faculty of Business management, Department of Business \\ Finance, Bratislava
}

\begin{abstract}
The paper focuses on how social media usage by children determines their interactions with consumer brands. First it describes how and when young children develop brand awareness and which are the most important predictors of this development. Those findings are then put in connection with the impact of social media. We elaborate on a deeper level how children approach online communications with brands in the social media context. Our assumptions are supported by a research conducted on a group of New Zealand children, both boys and girls in the age group of 11-14 years. This qualitative approach was implemented using in-depth interviews and identifies three key modes of brand interaction behaviour when young consumers use social media. According to these findings we assume that there is a connection between the use of social media and children's relationship with consumer brands.
\end{abstract}

\section{Introduction}

This article aims to explore based on previous research, how children interact with brands through social networks. Children are active users of social networks. According to previous findings, almost $70 \%$ of Slovak children actively use a profile on social networks or game sites. Concerning age categories, it can be stated from the data that a third of children aged 9-10 years, and up to $69 \%$ of children aged 11-12 years, use social media [1]. Therefore, understanding the nature of children's interaction with brands on social networks is also crucial for companies. Social networks offer companies many opportunities to understand children's consumer behavior and thus continuously and effectively build children's relationships with brands as relationships of potential customers.

We define children as a target group and describe the development of their brand knowledge in this article. We also analyze and elaborate on their consumer development and behavior. Furthermore, we assume the influence of social networks on the relationship of children with brands. We support our assumptions about the issue by research conducted on a small group of New Zealand children about whom we presumed that their interaction with brands through social networks would be similar to that of children in Slovakia in terms of the frequency of social network use.

\footnotetext{
* Corresponding author: nikoleta.hutmanova@euba.sk
} 
We implemented a qualitative approach using both paired and individual in-depth interviews of New Zealand children (boys and girls) in the age group of 11-14 years. We analyzed the data by thematic transcript analysis of interviews. At the end of the research, based on the respondent's answers, it was possible to create a conceptual model that illustrates the main processes based on which children use social networks to interact with brands.

\section{Literature and background}

\subsection{Development of children's brand knowledge}

Children worldwide became an essential and unique market segment in the sixties of the twentieth century. This understanding of children as independent consumers has grown over time and continues to grow. According to this fact, marketing specialists started to deal with children and adolescents as a separate target group for several reasons. One of them is that it is not uncommon for children to receive both material gifts and money from their relatives. As a result, children begin to realize the value of money and decide what products they would like to buy at a young age. Based on this, children are already perceived as customers who have a certain power and even have the ability to influence their parents [2].

According to findings, children's consumer behavior develops at an early age. Two fundamental factors influence the process by which children become consumers: cognitive and environmental factors. Cognitive factors are children's abilities based on their age. Environmental factors apply to families (especially mothers), peers, and the media [3].

Knowing when and how children learn brand names and how they remember them in the process of becoming consumers is generally explained by Piaget's theory of cognitive development. In Piaget's theory, there are two developmental stages related to developing the faculty of understanding symbolism most closely. These phases are the preoperative and specific operative phase [3]. Research has shown that information about the brand increases in children as they cognitively develop. Ward et al. [4] reported in their study that brand information is increasing with age and that even preschoolers can remember brand names from different product categories.

The purpose of one of the studies in this area was to use selected clues to find out when children's brand awareness starts to develop. A total of 66 Turkish children aged 3 to 5 attending preschool took part in the research. Individual interviews were conducted with them in order to determine their awareness of selected brands. The results of this research show that brand awareness development takes place at the age of 3 years. Even 3 -year-olds remembered specific brands and products after seeing the logo, packaging, and character of the brand. Brand awareness shows a directly proportional increase in age. Moreover, brand knowledge reaches its highest level at the age of 12 [5].

\subsubsection{Impact of the theory of mind on children's brand knowledge}

The cognitive perspective suggests that the individual differences between children, and their social development, can only be assessed once they have developed a so-called theory of mind. American psychologists Premack and Woodruff were the first to define the concept of the theory of mind. According to them, the theory of mind refers to the ability to think about the mental states of others. Thanks to this ability, individuals are further able to understand and predict the behavior of others. A good level of mastery of the theory of mind allows an individual to express different reactions in different social situations. Terms 
such as "mind-reading" or "mentalization" are also used in literature to describe this term in more detail [6].

In other words, the theory of mind explains that children need to develop the ability to understand another person's perspective because they need a mental basis to comprehend that there are different representations of the world [7]. These representations also apply to trademarks symbolizing the desired attributes of selected products. For instance, quality, prestige, warmth, comfort, and "coolness". The development of the theory of mind in this context allows children to recognize these attributes in a particular brand [3].

Other principal prerequisites for children's understanding of brands relate to their ability to develop their knowledge of market phenomena, such as what brands mean to people and how to understand their persuasive intent [7]. The theory of mind and the enhancement of powerful functional abilities form an essential developmental element for children that enables them to simultaneously understand brand symbolism and develop brand awareness to foster interaction with brands relevant to them [8].

Children's direct experience with brands can help them learn more about brand attributes and discriminate between brands later. Knowing brands helps children shape their preferences because it makes them differentiate between market incentives (Bahn, 1986) [9]. Learning from direct experience also leaves memory traces that help children with later recognition and memorization of the brand [10].

Nowadays, however, the Internet is a central medium in the whole process of consumer behavior. The use of digital technologies has shown an improvement in the memory of young teenagers, the organization of stored information, and an overall improvement in cognitive activity [11]. These benefits of actively using digital media are potentially beneficial elements in helping children build their relationships with brands.

\subsubsection{Impact of social media on children's brand knowledge}

The As already mentioned, children's interactions with consumer brands are in social contexts no longer limited to family relationships. Since children are active users of social networks, understanding the nature of this interaction is vital. Mainly because social networks offer companies more opportunities to connect customers with brands [12].

Previous research has examined the impact of advertising on children's brand perceptions. However, these studies have not sufficiently dealt with how children interact with consumer brands through social networks, and little is known about how children use social networks to interact with the brand or how it affects their behavior and brand relationship.

Research has suggested that children use social media for entertainment, socializing with friends, and developing their identities [13]. Changing trends in social network usage, such as the increase in media streaming, enabled children to access content through the Internet at home more [14].

The possibilities of brand interaction differ from platform to platform based on how these social media platforms are constructed. For example, children can indicate their affiliation to a brand by communicating on YouTube with a well-known vlogger. Such interactions create the perception of a two-way relationship with the celebrity brand in the form of a parasocial interaction [15]. These types of interactions create feelings of intimacy, we expect them to contribute to the positive affiliation of children with brands and help children gain market and brand knowledge.

Friendly interactions of children on social media platforms are interesting for marketers because the users, in this case, children, can potentially learn about consumer brands. Therefore, marketers strive to make children learn more about consumer brands through 
commercial placements or sponsored posts. Using social media, in this fashion, makes it easier for children to acquire brand knowledge and builds an affiliation with brands that are expected to determine the quality of their relationship with each other. Under these circumstances, the brand might develop various new strategies that are able to achieve involvement with a specific target group in an online environment. Advanced online branding strategies for the media allow the market to create direct, interactive, and social relationships between brands and young consumers [16].

The understanding of the persuasive side of advertising develops in children between the ages of 10 and 12. Children at this age already understand that ads and brands are able to cause changes in thinking and attitudes and can also influence their shopping intent. On the other hand, from the strategic standpoint of marketers, this age of children is perceived as the one that can be most effectively used to change the attitudes of children as potential future customers [17].

\section{Investigation of the influence of social networks on the children's relationship with brands}

The qualitative research conducted through paired and individual in-depth interviews with New Zealand children offers insights on how to deepen children's understanding of their online brand communication in the context of social media. Research has shown that children's social media utilization is more active and dynamic than presented in the past. It is an important finding for the inquiry into children's relationship with brands.

For marketers, the research process can provide specific data to help children understand the brand's commercial intent and its practices on social media. The findings also clarify the extent of young consumers' interactive behavior and provide information on how children get to know the brand, how they respond to their communication on social media, and how they subsequently evaluate this communication [18].

Based on the data obtained from interviews with boys and girls in the age group of 11 to 14 years, it was concluded that in the context of children's interaction with brands on social networks, there were three main processes shown in Figure 1 that take place.

Discerning - the subprocesses of recognition are the perception of a brand, which with recognizing the brand represent a lower level of interaction. They already include a specific internalized knowledge of the brand.

Reacting - consists of a description of the brand, which covers a passive and active interaction. Therefore, it represents a more dynamic interaction resulting in the shaping of children's opinions.

Forming - may involve interaction through remote "observation" or behavior in which a more active relationship manifests, mainly if the child actively uses multiple social media platforms. Most of the children interviewed used at least two social networking platforms. Some children used up to three or more networks, and most of them had a favorite, preferred social media network [18]. 


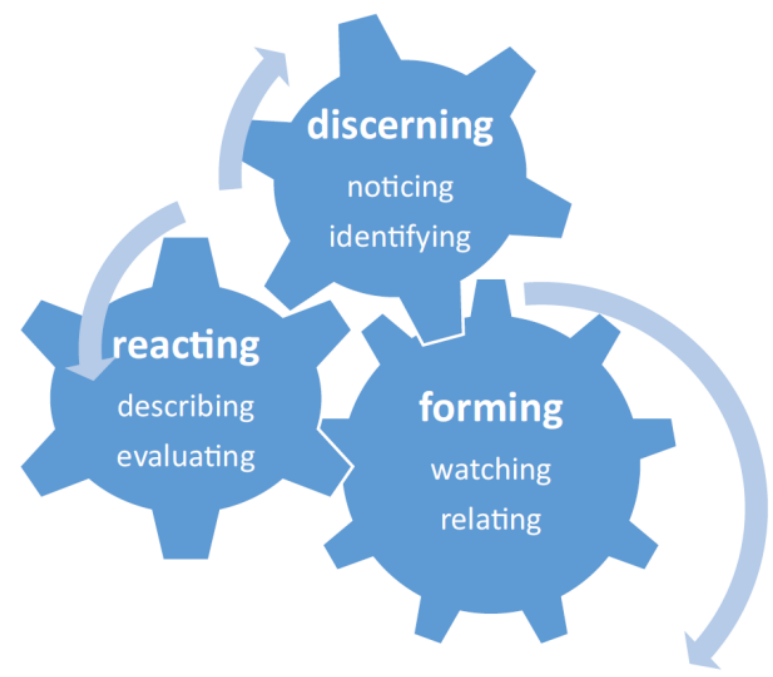

Fig. 1. Conceptual model: children using social media for brand interactions Jones \& Glynn, 2019 [18].

In this study, the mentioned processes show a range of interactive behaviors, with specific behavioral manifestations on social media. They confirm that children are able to build relationships with brands through a combination of interaction processes and that some of the established relationships with brands are more dynamic than others. Marketers might find these results particularly interesting. Moreover, people offering branded products and services in a child consumer market might also find them beneficial. The findings clarify the extent to which young consumers' behavior interacts and provide information on how children

\section{Conclusion}

According to secondary data, we have found that children have become a fascinating and attractive market segment in recent years. Their developmental cognitive perspective suggests that children's consumer behavior appears at an early age. The advances of modern digital technology have an increasing effect on this behavior over time, mainly through social media platforms. Children were presented with a range of interactive types of behavior that clarified the extent of their interaction. Comprehending it enables marketers to create interactive social relationships between brands and young consumers more effectively.

The findings of the mentioned case study have several important implications for future practice. On the other hand, it is salient to note that the research sample of 23 respondents may not be sufficient to express a clear conclusion applicable to all or precisely most child consumers in Slovakia. Nevertheless, we believe that the respondents were able to answer questions that focused on the range of social media platforms they used and to detect what kind of marketing content they could perceive and how they interact with it. The most striking result emerging from the data is that based on this qualitative research, it was possible to compile the presented conceptual model of social network usage processes of children interacting with brands, which we believe should be a basis for further research. 
The article is an output of research project VEGA (1/0240/20) "Financial Aspects of Sustainable Business - Enterprise Succession Solution for Small and Medium-sized Enterprises".

\section{References}

1. P. Izrael, J. Holdoš, M. Hasák, Sociálne siete a excesívne použivanie internetu a sociálnych médií (Správa z výskumu EU Kids Online IV na Slovensku). Ružomberok: Katolícka univerzita v Ružomberku (2019)

2. V.M. Somesfalean, Children as target market. Studies in Business \& Economics, 7, 172183. ISSN 1842-4120 (2012)

3. A.R. McAlister, T.B. Cornwell, Children's brand symbolism understanding: links to theory of mind and executive functioning. Psychology and Marketing, 27, 203-228. ISSN: $1520-6793$ (2010)

4. S. Ward, D. Wackman, E. Wartella, The development of consumer information processing skills: integrating cognitive development and family interaction theories. Advances in Consumer Research, 5, 535-539. ISSN: 00989258 (1977)

5. Y.A. Arnas, I. Tas, I.G. Ogul, The development of Brand awareness in young children: how do young children recognize brands? International Journal of Consumer Studies, 40, 36-542. ISSN: 1470-6431(2016)

6. A.I. Goldman, Theory of mind. Oxford Handbook of Philosophy and Cognitive Science. ISBN: 9780195309799 (2012)

7. L.J. Moses, D.A. Baldwin, What can the study of cognitive development reveal about children's ability to appreciate and cope with advertising? Journal of Public Policy \& Marketing, 24, 186-201. eISSN: 15477207(2005)

8. P.M. Valkenburg, Identifying determinants of young children's brand awareness: television, parents, and peers. Journal of Applied Developmental Psychology, 26, ISSN: 0193-3973 (2005)

9. K.D. Bahn, How and when do brand perceptions and preferences first form? A cognitive developmental perspective, Journal of Consumer Research, 13, 382-393. ISSN: 1537-5277 (1986)

10. K.L. Keller, Brand synthesis: the multidimensionality of brand knowledge. Journal of Consumer Research, 29, 595-600. ISSN: 0093-5301 (2003)

11. P.Q. Brito, Pre-teens and teens conceptualization of electronic games and internet. $20128^{\text {th }}$ International Conference on Information Science and Digital Content Technology (ICIDT), IEEE. Vol. 3, p. 621-625. ISSN: 0018-9219 (2012) 
12. J. Ahn, What can we learn from Facebook activity? Using social learning analytics to observe new media literacy skills. Proceedings of the Third International Conference on Learning Analytics and Knowledge 8-12 April, Leuven,135-144 (2013)

13. L. Anderson, D.B. McCabe, A co-constructed world: adolescent self-socialization on the internet. Journal of Public Policy \& Marketing. 31, 240-253. eISSN: 15477207 (2012)

14. M.R. Nelson, L. Atkinson, M.A. Rademacher, R. Ahn, How media and family build children's persuasion knowledge. Journal of Current Issues \& Research in Advertising, 38, 165-183. ISSN: 2164-7313 (2017)

15. H.U. Khan, A. Daud, U. Ishfaq, T. Amjad, N. Aljohani, R.A. Abbasi, J.S. Alowibdi, Modeling to identify influential bloggers in the blogosphere: a survey, Computers in Human Behavior, 68, 64-82. ISSN: 07475632 (2017)

16. S.C. Boerman, L.M. Willemsen, E.P. Van Der Aa, "This post is sponsored": effects of sponsorship disclosure on persuasion knowledge and electronic word of mouth in the context of Facebook. Journal of Interactive Marketing, 38, 82-92. ISSN: 1094-9968 (2017)

17. P. Nuñez-Gomez, J. Sánchez-Herrera, T. Pintado-Blanco, Children's Engagement with Brands: From Social Media Consumption to Brand Preference and Loyalty. Sustainability, 12, 9337. ISSN 2071-1050 (2020).

18. K. Jones, M. Glynn, How children use social media for brand interactions. Young Consumers, 20, 91-108. ISSN: 1747-3616 (2019) 